\title{
Catalyst-free ceramic-carbonate dual phase membrane reactor for hydrogen production from gasifier syngas
}

\author{
Xueliang Dong and Y. S. Lin*
}

School for Engineering of Matter, Transport and Energy, Arizona State University, Tempe, Arizona 85287, USA

*Corresponding author. Tel.: +1 480965 7769, Fax: +1 4809650037.

E-mail address: jerry.lin@asu.edu (Y.S. Lin). 


\begin{abstract}
Ceramic-carbonate dual phase dense membranes are a new group of inorganic membranes with perm-selective to $\mathrm{CO}_{2}$ at high temperatures. This paper reports a new catalyst-free tubular membrane reactor to shift $\mathrm{CO}$ from the hot gasifier syngas to $\mathrm{H}_{2}$ and $\mathrm{CO}_{2}$ with simultaneous separation of $\mathrm{CO}_{2}$. The membrane reactor is based on a samarium-doped ceria (SDC)-carbonate dual phase membrane which removes $\mathrm{CO}_{2}$ facilitating conversion of $\mathrm{CO}$ to $\mathrm{H}_{2}$ at high temperatures. The results show that catalytic-free membrane reactor can convert $\mathrm{CO}$ to $\mathrm{H}_{2}$ and $\mathrm{CO}_{2}$ with removal of $\mathrm{CO}_{2}$ at temperatures above $800{ }^{\circ} \mathrm{C}$. At $900{ }^{\circ} \mathrm{C}$, the membrane reactor gives $\mathrm{CO}_{2}$ flux of $2.7 \times 10^{-3} \mathrm{~mol} \cdot \mathrm{m}^{-2} \cdot \mathrm{s}^{-1}$, CO conversion and $\mathrm{CO}_{2}$ recovery of $26.1 \%$ and $18.7 \%$, respectively, much higher than the conventional fixed bed reactor under identical conditions. Temperature, steam to CO ratio, and syngas feed flow rate are key parameters to control the reaction performance. Increase of the feed pressure (reaction side) is an effective strategy to improve the reactor performance and $\mathrm{CO}_{2}$ recovery. The membrane reactor shows high thermal and chemical stability under syngas WGS reaction environment. This work demonstrates potential of using catalyst-free SDC-carbonate dual phase membrane reactor for water gas shift reaction to convert $\mathrm{CO}$ to $\mathrm{H}_{2}$ with $\mathrm{CO}_{2}$ capture.
\end{abstract}

Keywords: Gasification; Syngas; Membrane reactor; $\mathrm{CO}_{2}$ separation; Hydrogen 


\section{Introduction}

As one of the promising strategies to effectively reduce carbon dioxide $\left(\mathrm{CO}_{2}\right)$ emissions, pre-combustion $\mathrm{CO}_{2}$ capture in the integrated gasification combined cycle (IGCC) power plant has attracted considerable interest from both academia and industry [1-3]. In this process, carbonaceous fuels are gasified at high temperature (may exceed $1500{ }^{\circ} \mathrm{C}$ ) to produce high pressure (20-40 bar) syngas [4], comprised mainly of hydrogen $\left(\mathrm{H}_{2}\right)$, carbon monoxide (CO) and $\mathrm{CO}_{2}$, which is further converted to more $\mathrm{H}_{2}$ through the water gas-shift (WGS) reaction, resulting in high pressure $\mathrm{CO}_{2}$ and $\mathrm{H}_{2}$. Separation of these two components allows for the storage of $\mathrm{CO}_{2}$, while $\mathrm{H}_{2}$ can be used for power generation.

Membrane technology has great potential for both $\mathrm{H}_{2}$ and $\mathrm{CO}_{2}$ separation within this gasification process [5-8]. Several types of $\mathrm{H}_{2}$ selective membranes, such as palladium-based metallic membranes [9,10], proton-conducting dense ceramic membranes [11,12], silica membranes $[13,14]$ and zeolite membranes $[15,16]$, have been studied as membrane reactors for simultaneously shift reaction and $\mathrm{H}_{2}$ separation. In this type of membrane reactors, $\mathrm{H}_{2}$ permeates through the membrane reactor and is collected as a low pressure stream. Considering that WGS is an exothermic reaction, traditional two-stage WGS membrane reactors always operate at relatively low temperature $\left(<400{ }^{\circ} \mathrm{C}\right)$ to achieve high $\mathrm{CO}$ conversion. However, the low operation temperature imposes a considerable cooling penalty on the gasifier syngas, which is a formidable economic disadvantage [5]. To avoid the cooling of syngas to a large extent, the high temperature WGS reaction was proposed by the researchers at US National Energy Technology Laboratory (NETL) [17-18]. WGS reaction was operated in a Pd-Cu membrane reactor at $900{ }^{\circ} \mathrm{C}$. High CO conversion can be obtained at a relatively long residence time [19]. However, the poor stability of the metallic membrane at such high reaction temperature limited its practical application.

Besides the in-situ separation of $\mathrm{H}_{2}, \mathrm{CO}_{2}$ removal has been confirmed as another promising route to promote the WGS reaction for $\mathrm{H}_{2}$ production. Typically, $\mathrm{CO}_{2}$ sorbents were used for in situ $\mathrm{CO}_{2}$ removal to enhance the reaction performance [20-22]. It is also highly desirable to use a $\mathrm{CO}_{2}$-selective membrane for the WGS reaction because $\mathrm{CO}_{2}$-selective membrane reactors have the potential to achieve higher $\mathrm{H}_{2}$ recovery [5]. 
Moreover, $\mathrm{CO}_{2}$ removal through the membrane retains $\mathrm{H}_{2}$ at high pressure, maximizing the efficiency of the combustion turbine. Scholes et al. [5] also stated that if $\mathrm{CO}_{2}$-selective WGS membrane reactors can be adapted to operate at high temperatures and pressures they will present an attractive option for the IGCC process.

However, the development of membranes that can retain the small molecular $\mathrm{H}_{2}$ but permeate the larger $\mathrm{CO}_{2}$ is a significant challenge. Many polymeric membranes show $\mathrm{CO}_{2}$ perm-selectivity $[7,23,24]$. However, these membranes are not stable in the membrane reactor environments at elevated temperature. Inorganic membranes exhibit better thermal and chemical stability and have been studied in recent years for $\mathrm{CO}_{2}$ separation [25-28]. The separation process is controlled by the preferential adsorption mechanism of $\mathrm{CO}_{2}$. Several inorganic membranes exhibit high $\mathrm{CO}_{2}$ perm-selectivity at room temperature, but at higher temperatures $\left(>400{ }^{\circ} \mathrm{C}\right)$ their selectivity diminishes due to the low $\mathrm{CO}_{2}$ adsorption. Consequently, there is a compelling need for $\mathrm{CO}_{2}$ separation membranes that can operate under more extreme conditions while providing a high performance for sustainable $\mathrm{CO}_{2}$ capture.

In an effort to develop $\mathrm{CO}_{2}$ perm-selective membranes, Lin and co-workers were the first to report synthesis and $\mathrm{CO}_{2}$ permeation of a metal-carbonate [29] and ceramic-carbonate [30] dual-phase membranes for $\mathrm{CO}_{2}$ separation. These dual-phase membranes have high $\mathrm{CO}_{2}$ permeance with theoretically infinite selectivity for $\mathrm{CO}_{2}$ over all other gases in 700-900 ${ }^{\circ} \mathrm{C}$ [29-41]. A typical dual-phase membrane is composed of a ceramic phase and a molten carbonate phase. The ceramic phase serves as a porous support and also an oxygen ion $\left(\mathrm{O}^{2-}\right)$ conductor, while the molten carbonate phase is infiltrated into the porous support as a carbonate-ion $\left(\mathrm{CO}_{3}{ }^{2-}\right)$ conductor. At high temperatures, $\mathrm{CO}_{2}$ combines with $\mathrm{O}^{2-}$ to be $\mathrm{CO}_{3}{ }^{2-}$ which transports through the membrane under the driving force of $\mathrm{CO}_{2}$ partial pressure gradient.

Inspired by the striking property of dual-phase membranes, here we proposed a new membrane reactor to convert $\mathrm{CO}$ from the hot gasifier syngas to $\mathrm{H}_{2}$ and $\mathrm{CO}_{2}$ with simultaneous separation of $\mathrm{CO}_{2}$, as shown in Figure 1. The in situ removal of $\mathrm{CO}_{2}$ from reaction zone can break the thermodynamic equilibrium limitation and significantly enhance the CO conversion of the WGS reaction. Moreover, at high temperatures (above $700{ }^{\circ} \mathrm{C}$ ) the 
homogeneous WGS reaction rate could be sufficiently high to avoid the use of a WGS catalyst for the CO conversion. The catalyst-free WGS membrane reactor could result in substantial saving in the capital cost and great simplification in membrane reactor design. To the best of our knowledge, this unique idea has never been attempted. The successful implementation of this new technology could open the door for innovative process designs for high-efficiency IGCC power plant with $\mathrm{CO}_{2}$ capture. The present work is aimed at demonstration of the feasibility of this idea.

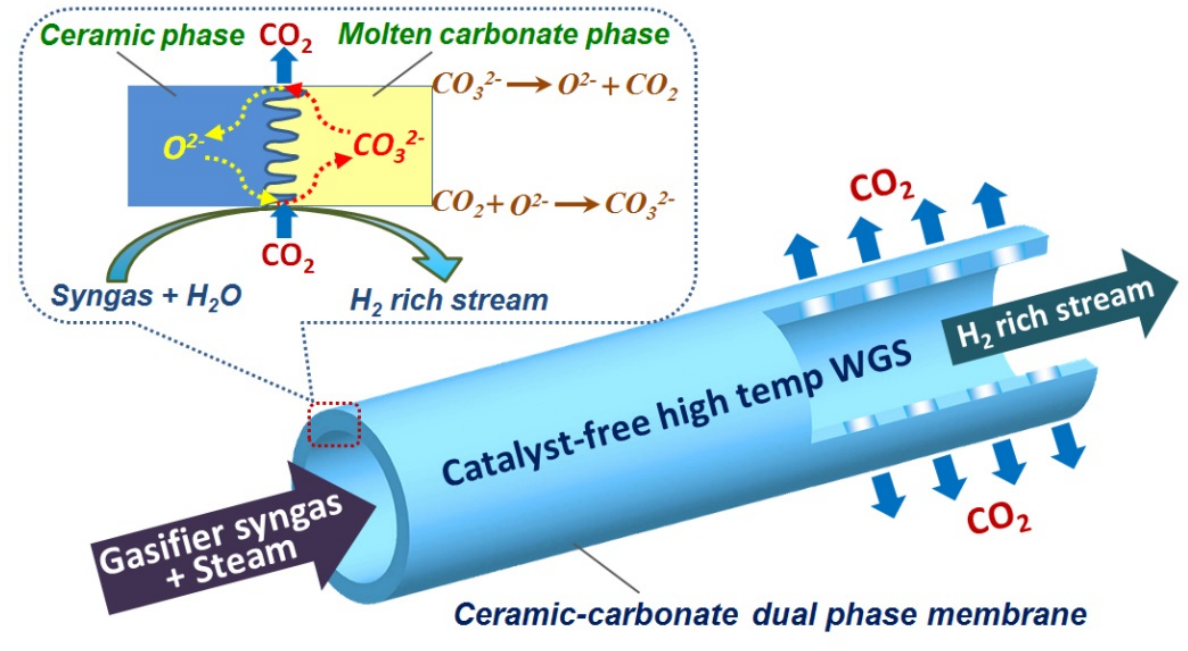

Figure 1: Schematic of catalyst-free ceramic-carbonate dual phase membrane reactor for syngas WGS reaction.

\section{Experimental}

\subsection{Tubular dual phase membrane synthesis and characterization}

$\mathrm{Sm}_{0.2} \mathrm{Ce}_{0.8} \mathrm{O}_{1.9}$ (SDC) powder was synthesized via the citrate method from the metal nitrates [34,35]. Stoichiometric amounts of $\mathrm{Ce}\left(\mathrm{NO}_{3}\right)_{3} \cdot 6 \mathrm{H}_{2} \mathrm{O}$ (Alpha Aesar) and $\mathrm{Sm}\left(\mathrm{NO}_{3}\right)_{3} \cdot 6 \mathrm{H}_{2} \mathrm{O}$ (Alpha Aesar) were mixed into deionized water, followed by the addition of citric acid (mole ratio of total metal ions to citrate is 1:2) with stirring. The solution containing the complex precursor was then heated on a hot plate to 200-300 ${ }^{\circ} \mathrm{C}$. Upon heating, the solution boiled and formed a gel. The gel underwent a dehydration and decomposition process and produced a foam-like solid, which ignited to produce a soft and fluffy product. 
Finally, the products were calcined in air at $550^{\circ} \mathrm{C}$ for $5 \mathrm{~h}$ to prepare SDC oxide.

SDC tubular substrate was prepared using a centrifugal casting method as reported in our previous work [34]. About $50 \mathrm{wt} \%$ SDC, 50wt\% water and a few drops of PVA solution were mixed and ball milled at $175 \mathrm{rpm}$ for 3h to prepare homogeneous SDC slurry. The SDC slurry was poured into the stainless steel mould with an inner diameter of $1.2-1.3 \mathrm{~cm}$. After centrifugation on a homemade machine for $20 \mathrm{~min}$ at the spin rate of $4000 \mathrm{rpm}$, the green tubes were dried in a humidity chamber at $40{ }^{\circ} \mathrm{C}$ with a relative humidity of $60 \%$ for $12 \mathrm{~h}$. Then, the tubes were sintered at $1420{ }^{\circ} \mathrm{C}$ for $12 \mathrm{~h}$. The thickness of the SDC tube could be controlled by the amount of the added SDC slurry. SDC tubular supports with the thickness of $1.5 \mathrm{~mm}$ were prepared.

SDC-carbonate dual-phase membranes were obtained via a direct infiltration of molten carbonates into the SDC supports by the method described in our previous work [34]. Lithium ( $\mathrm{Li})$, sodium (Na), and potassium (K) carbonates from Alpha Aesar $\left(\mathrm{Li}_{2} \mathrm{CO}_{3}, 99.2 \%\right.$; $\mathrm{Na}_{2} \mathrm{CO}_{3}, 99.9 \% ; \mathrm{K}_{2} \mathrm{CO}_{3}, 99.8 \%$ ) were mixed in the mole ratio of $42.5 \%$ : $32.5 \%: 25 \%$ and heated to $600{ }^{\circ} \mathrm{C}$ in a box furnace. The porous SDC supports were preheated in the furnace, then vertically dipped into the molten carbonate and held for 1h. After removing the excess carbonate on the surface, the dual-phase membranes were obtained.

The morphologies of the substrates and membranes were examined by scanning electron microscopy (SEM) (Philips FEI XL-30) after gold deposition. The gas-tightness of the dual-phase membranes was tested before the high temperature gas permeation. In testing the gas-tightness, the membrane was assembled into a tubular permeation cell sealed with epoxy resin. $\mathrm{N}_{2}$ was fed to the tube side and the shell side was connected to a soap bubble flowmeter. The feed pressure was $0.3 \mathrm{MPa}$. If no obvious $\mathrm{N}_{2}$ flow rate was observed on the soap bubble flowmeter in $3 \mathrm{~h}$, the membrane was considered to be gas tight. Only gas tight membranes (without defects) was used for $\mathrm{CO}_{2}$ separation and membrane reactor experiments. The crystal phases of the samples were determined by X-ray diffraction (XRD) with $\mathrm{Cu} \mathrm{Ka}$ radiation (Bruker, AXS-D8,). Diffraction patterns were collected at room temperature in the range of $20^{\circ}<2 \theta<80^{\circ}$, with a step width of $0.05^{\circ}$ and a scan rate of $0.2 \mathrm{~s}$ per step. 


\subsection{Syngas water gas shift reaction}

The tubular dual-phase membranes with the thickness of $1.5 \mathrm{~mm}$ and length of around 2.5 cm were used. The schematic diagram of the set-up was shown in Figure $2 . \mathrm{N}_{2}$ as a carry gas took water and simulated syngas $\left(49.5 \% \mathrm{CO}, 36 \% \mathrm{CO}_{2}, 10 \% \mathrm{H}_{2}\right.$ and $4.5 \% \mathrm{~N}_{2}$ ) into the tube side of the membrane. $\mathrm{CO}_{2}$ permeated through the membrane to the outer side and was swept out by helium. Although no catalyst was used, WGS reaction occurred during the removal of $\mathrm{CO}_{2}$ to produce more $\mathrm{H}_{2}$ and $\mathrm{CO}_{2}$. The compositions of feed-out and sweep-out gases were analyzed using a gas chromatography (GC, Agilent 6890 N with a column of HayeSep DB 100/120, AllTech). The flow rates of both feed-out and sweep-out gases were measured by a soap film flow meter. The CO conversion $\left(X_{c o}\right)$ was calculated as follows.

$$
\mathrm{X}_{\mathrm{co}}=\frac{F_{C O}^{\text {feed in }}-F_{C O}^{\text {feed out }}-F_{C O}^{\text {sweep out }}}{F_{C O}^{\text {feed in }}} \times 100 \%
$$

where $F_{c o}{ }^{\text {feed in }}, F_{c o}{ }^{\text {feed out }}$, and $F_{c o}{ }^{\text {sweep out }}$ are CO flow rates of feed-in stream, feed-out stream and sweep-out stream, respectively. The $\mathrm{CO}_{2}$ recovery $\left(R_{c o 2}\right)$ was calculated as follows.

$$
\mathrm{R}_{\mathrm{co} 2}=\frac{F_{\mathrm{CO} 2}^{\text {sweep out }}}{F_{\mathrm{CO} 2}^{\text {feed }}+F_{\mathrm{CO} 2}^{\text {sweep out }}} \times 100 \%
$$

where $F_{c o 2}$ feed out , and $F_{c o 2}{ }^{\text {sweep out }}$ are $\mathrm{CO}_{2}$ flow rates of feed-out stream and sweep-out stream, respectively.

For traditional reactor, the membrane in Figure 2 was replaced by a dense alumina tube with the same size. The reaction occurred under the identical conditions with the syngas and steam. The leaked gas, if present, could be swept out by He. The CO conversion was calculated as Eq. 1. 


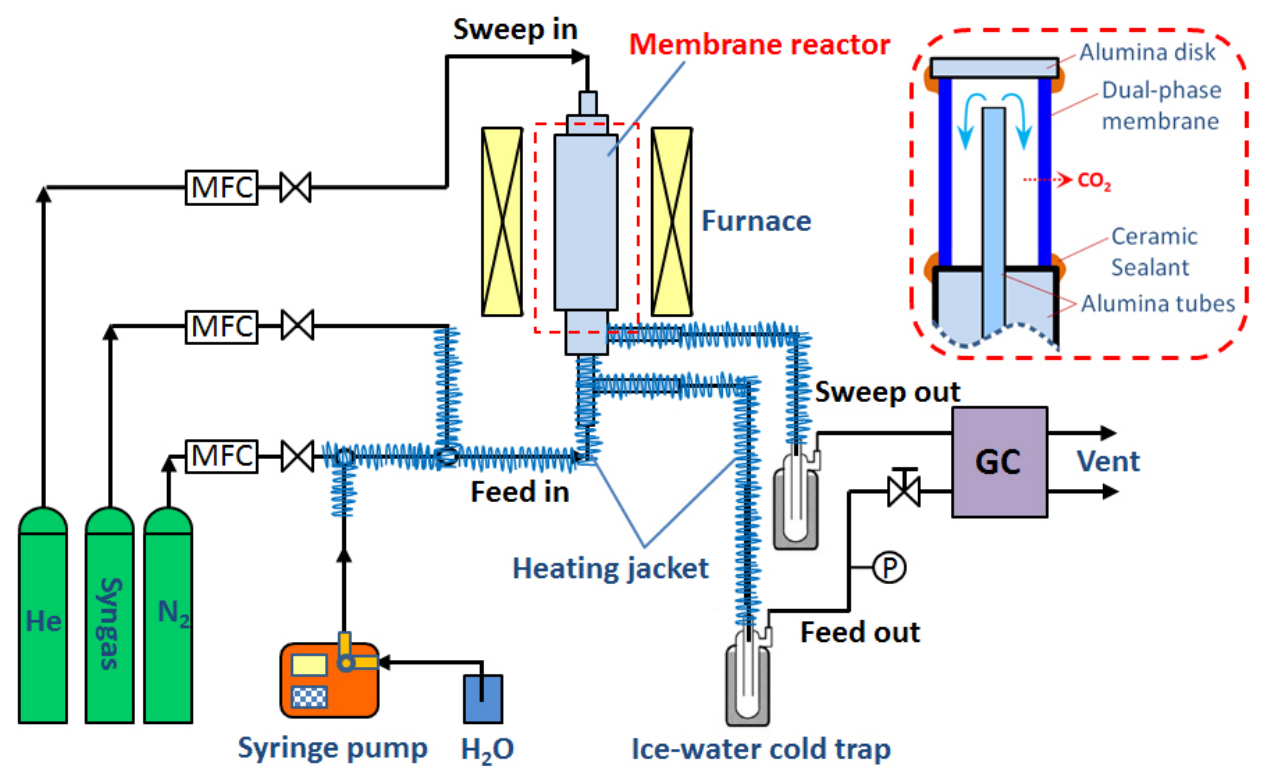

Figure 2: Schematic diagram of tubular SDC-carbonate dual phase membrane reactor for high temperature syngas WGS reaction.

\section{Results and discussion}

\subsection{Membrane morphology and $\mathrm{CO}_{2}$ permeation}

Figure 3 shows the morphology of tubular SDC supports and SDC-carbonate membranes. Using the centrifugal casting method, tubular SDC supports with different size can be prepared. SDC supports are porous with the porosity of about 35-40\% (Figures 3b and 3c). After infiltration with molten carbonates, the dense SDC-carbonate membranes are formed (Figures 3d and 3e). Clear dual-phase structure can be observed from the cross section (Figure 3f). The SDC and carbonate phases are well mixed. 

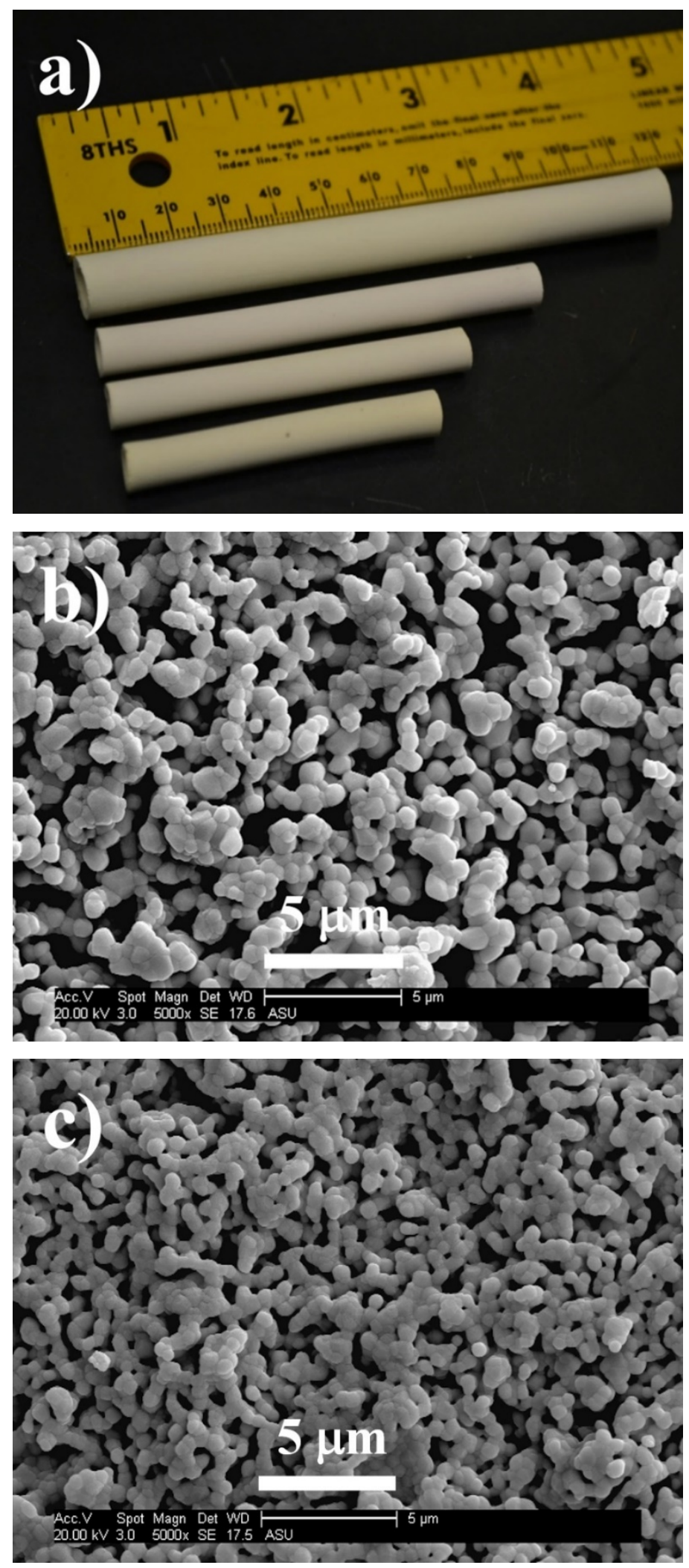

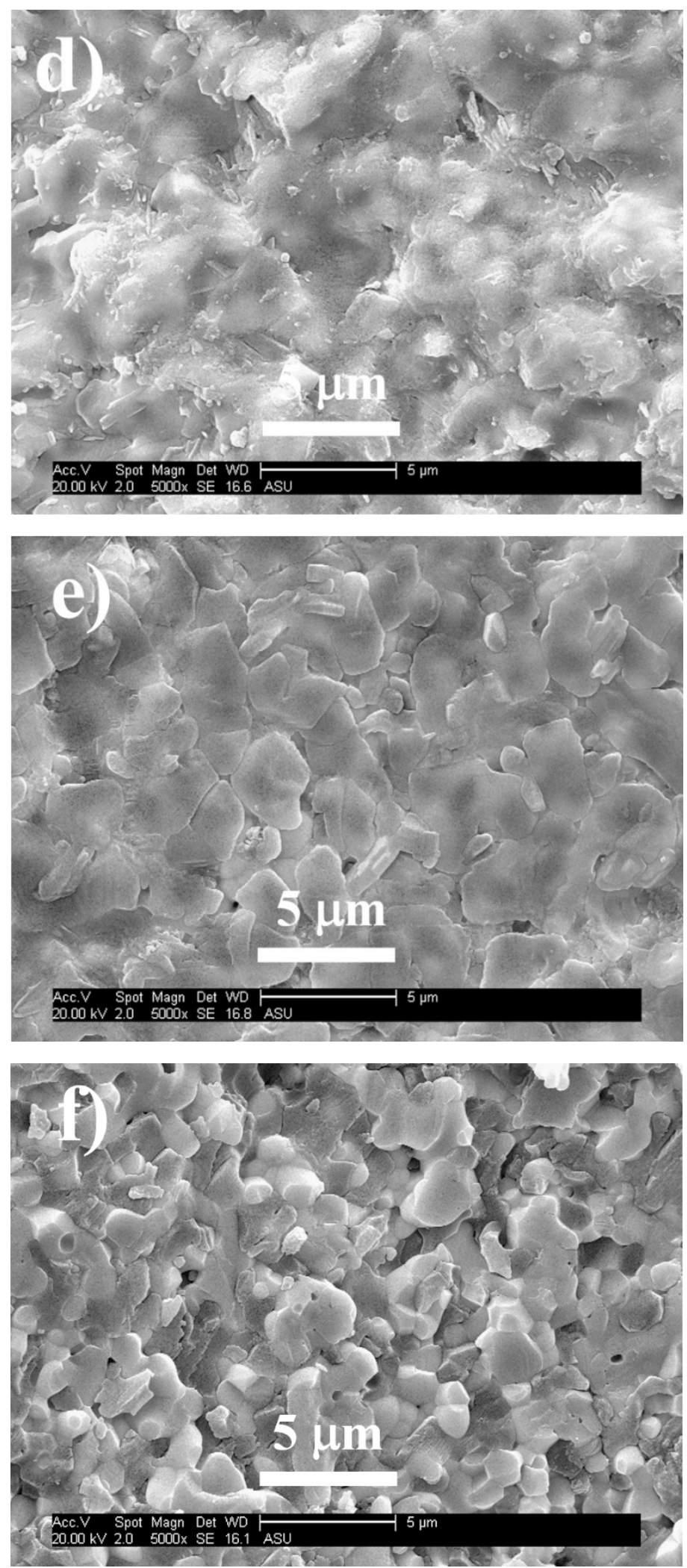

Figure 3: (a) Photo of SDC substrates with different sizes; SEM images: (b) outer and (c) inner surfaces of SDC substrate sintered at $1420{ }^{\circ} \mathrm{C}$ for $12 \mathrm{~h}$; (d) outer and (e) inner surfaces of SDC-carbonate membrane after infiltration; (f) cross section of SDC-carbonate membrane. 
First of all, the $\mathrm{CO}_{2}$ permeation flux of the dual phase membrane during the syngas WGS reaction was measured (Figure 4). $\mathrm{CO}_{2}$ permeation flux increases with temperature. At $900^{\circ} \mathrm{C}$, the flux is $2.7 \times 10^{-3} \mathrm{~mol} \cdot \mathrm{m}^{-2} \cdot \mathrm{s}^{-1}$. For comparison, the $\mathrm{CO}_{2}$ fluxes of the same membrane with $\mathrm{CO}_{2} / \mathrm{N}_{2}$ (1:1 in volume, or $50 \% \mathrm{CO}_{2}$ ) feed were also provided. Compared with the $\mathrm{CO}_{2}$ flux in $\mathrm{CO}_{2} / \mathrm{N}_{2}$ system, the relatively low flux in reaction process is attributed to the lower feed $\mathrm{CO}_{2}$ concentration [34]. In that temperature range, the $\mathrm{CO}_{2}$ concentration in the feed was $12 \%$ and in the feed-out was $12.5 \%-14.8 \%$ in $800-900^{\circ} \mathrm{C}$, with average $\mathrm{CO}_{2}$ concentration lower than $50 \%$ in the case with $\mathrm{CO}_{2} / \mathrm{N}_{2}$ feed. In the membrane reactor, the activation energy for $\mathrm{CO}_{2}$ permeation is estimated to be $90.8 \mathrm{~kJ} \cdot \mathrm{mol}^{-1}$, which is a little bit higher than that in $\mathrm{CO}_{2} / \mathrm{N}_{2}$ system $\left(83.3 \mathrm{~kJ} \cdot \mathrm{mol}^{-1}\right)$. This is caused by the fact that the average $\mathrm{CO}_{2}$ concentration in the feed, and hence the driving force for $\mathrm{CO}_{2}$ permeation, increases slightly with temperature. The higher apparent activation energy for permeation flux reflects contribution of the change in the driving force as temperature increases.

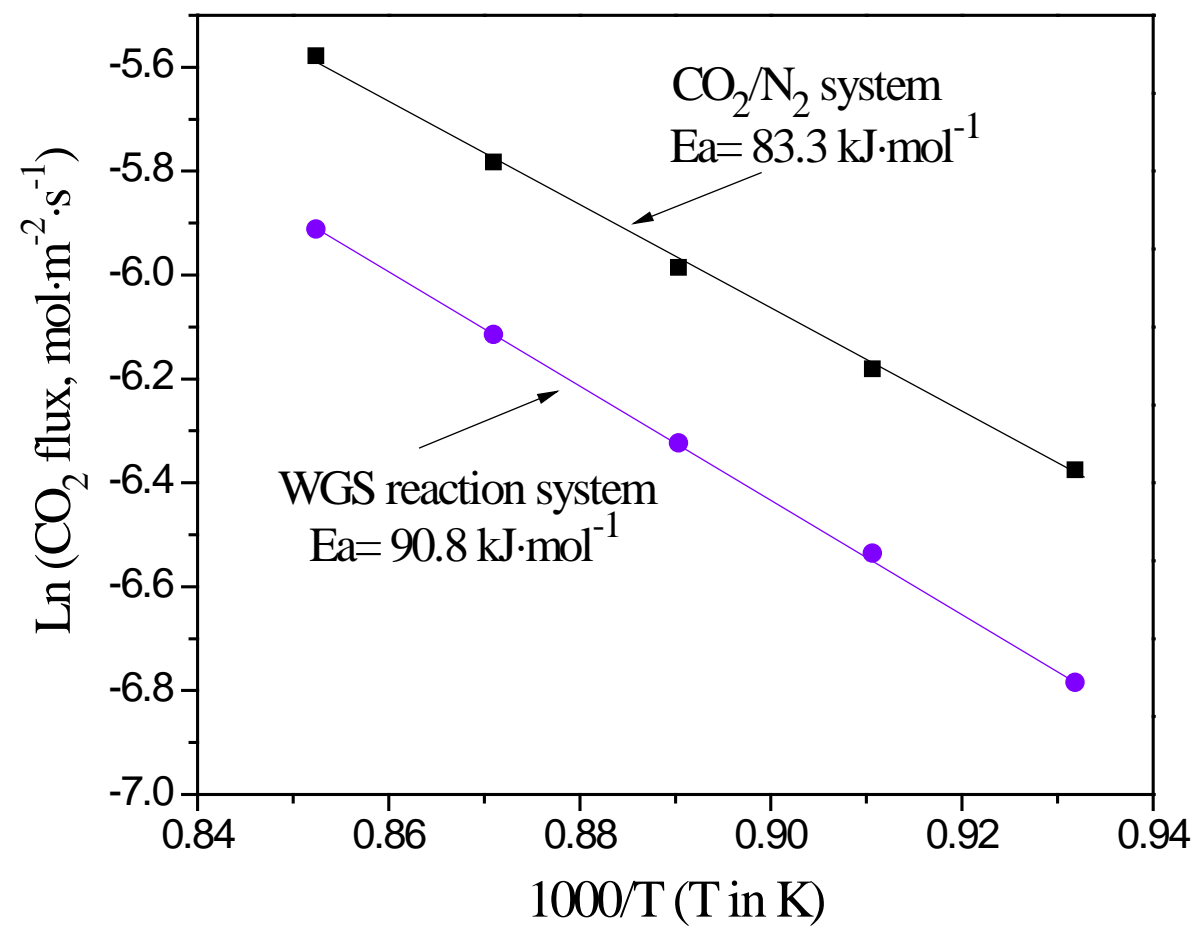

Figure 4: Arrhenius plots of the $\mathrm{CO}_{2}$ permeation flux of SDC-carbonate tubular dual-phase membranes in syngas WGS reaction system and $\mathrm{CO}_{2} / \mathrm{N}_{2}$ system. For syngas WGS reaction system, feed side: syngas flow rate $20 \mathrm{~mL} \cdot \mathrm{min}^{-1}$, $\mathrm{N}_{2}$ flow rate $10 \mathrm{~mL} \cdot \mathrm{min}^{-1}$, and $\mathrm{H}_{2} \mathrm{O}$ (steam) to CO molar ratio is 3.0; sweep side: He flow rate $60 \mathrm{~mL} \cdot \mathrm{min}^{-1}$. For $\mathrm{CO}_{2} / \mathrm{N}_{2}$ system, feed side: CO flow rate $25 \mathrm{~mL} \cdot \mathrm{min}^{-1}, \mathrm{~N}_{2}$ flow rate $25 \mathrm{~mL} \cdot \mathrm{min}^{-1}$; sweep side: He flow rate $60 \mathrm{~mL} \cdot \mathrm{min}^{-1}$. The pressure at feed and permeate sides are both $1 \mathrm{~atm}$ 


\subsection{WGS Reaction in Membrane Reactor}

For the high temperature syngas WGS reaction in the membrane reactor, temperature, steam to CO molar ratio and syngas flow rate are three critical parameters [42]. Accordingly, the effects of these parameters on the reaction performance were investigated. Figure 5 shows the temperature dependence of reaction performance of the dual phase membrane reactor. $\mathrm{CO}$ conversion and $\mathrm{CO}_{2}$ recovery increase from $15.1 \%$ to $26.1 \%$ and $9.6 \%$ to $18.7 \%$, respectively, as the temperature increase from 800 to $900{ }^{\circ} \mathrm{C}$. WGS reaction is an exothermal reaction, thus the high temperature is adverse for the conversion of CO. However, the in-situ removal of $\mathrm{CO}_{2}$ by the dual-phase membrane greatly promotes the shifting of the reaction equilibrium.

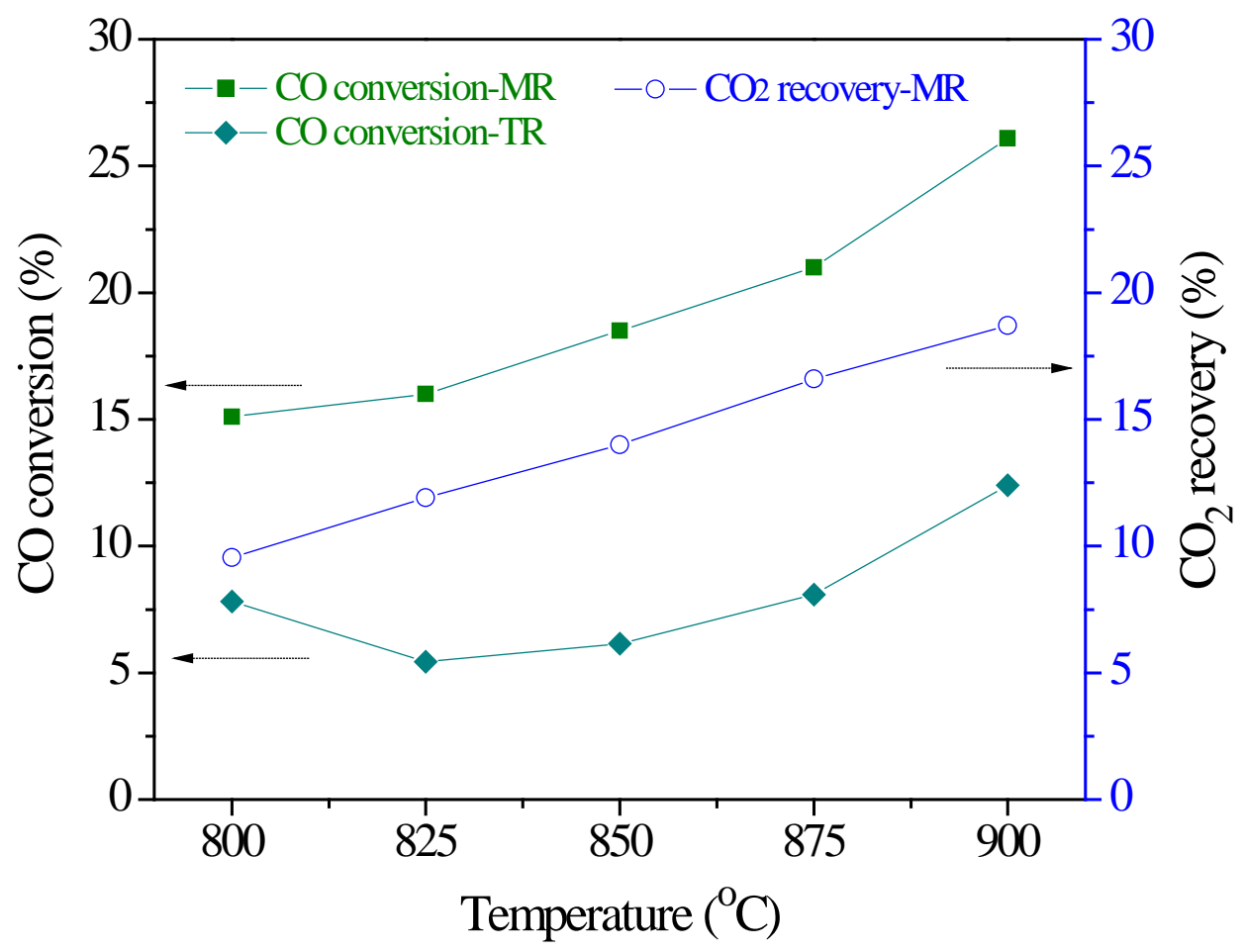

Figure 5: Performance of dual phase membrane reactor (MR) and traditional reactor (TR) for high temperature syngas water gas shift reaction as a function of temperature without catalyst. Feed side: simulated syngas flow rate $20 \mathrm{~mL} \cdot \mathrm{min}^{-1}, \mathrm{~N}_{2}$ flow rate $10 \mathrm{~mL} \cdot \mathrm{min}^{-1}$, and $\mathrm{H}_{2} \mathrm{O}$ (steam) to CO molar ratio is 3.0; Sweep side: He flow rate $60 \mathrm{~mL} \cdot \mathrm{min}^{-1}$. The pressure at feed and permeate sides are both 1 bar.

The increase of $\mathrm{CO}_{2}$ permeation flux with temperature results in the relatively high $\mathrm{CO}$ 
conversion at high temperature. For comparison, the results of a traditional reactor (a dense alumina tube with the same size) measured at the identical conditions are also provided in Figure 5. CO conversion of the traditional reactor is much lower than that of the membrane reactor. Furthermore, it decreases first and then increases upon increasing the temperature, which may be caused by the fact that the WGS reaction rate increases with temperature whereas the equilibrium conversion decreases from $74.1 \%$ at $800{ }^{\circ} \mathrm{C}$ to $68.7 \%$ at $900{ }^{\circ} \mathrm{C}$. These results indicate that using SDC-carbonate dual phase membrane reactor for high temperature syngas WGS reaction with simultaneous $\mathrm{CO}_{2}$ removal is technical feasible, and high temperature is favorable for the reaction.

Figure 6 presents the effect of steam to $\mathrm{CO}$ molar ratio $\left(\mathrm{H}_{2} \mathrm{O} / \mathrm{CO}\right.$ ratio $)$ on the reaction performance at $900{ }^{\circ} \mathrm{C}$. Upon increasing the $\mathrm{H}_{2} \mathrm{O} / \mathrm{CO}$ ratio, the $\mathrm{CO}$ conversion increases, while the $\mathrm{CO}_{2}$ recovery shows an opposite trend. When the $\mathrm{H}_{2} \mathrm{O} / \mathrm{CO}$ ratio is 4.0 , the $\mathrm{CO}$ conversion reaches $27.8 \%$ but the $\mathrm{CO}_{2}$ recovery is $17.4 \%$. The enhancement of $\mathrm{CO}$ conversation is more significant at the $\mathrm{H}_{2} \mathrm{O}$ /CO ratio of 1.0-3.0. However, further increase of $\mathrm{H}_{2} \mathrm{O} / \mathrm{CO}$ results in a relatively slow increase of $\mathrm{CO}$ conversation. This is attributed to that high $\mathrm{H}_{2} \mathrm{O} / \mathrm{CO}$ ratio reduces the residence time of the feed gases in the reactor since the $\mathrm{CO}$ flow rate is fixed. As is well known, short residence time is unfavorable for both CO conversion and $\mathrm{CO}_{2}$ recovery. In addition, excessive steam for the relatively high $\mathrm{H}_{2} \mathrm{O} / \mathrm{CO}$ ratio reduces the partial pressure of $\mathrm{CO}_{2}$ in the reaction side, resulting in the low $\mathrm{CO}_{2}$ permeation flux and low $\mathrm{CO}_{2}$ recovery. Therefore, in following experiments, the $\mathrm{H}_{2} \mathrm{O} / \mathrm{CO}$ ratio is fixed as 3.0. 


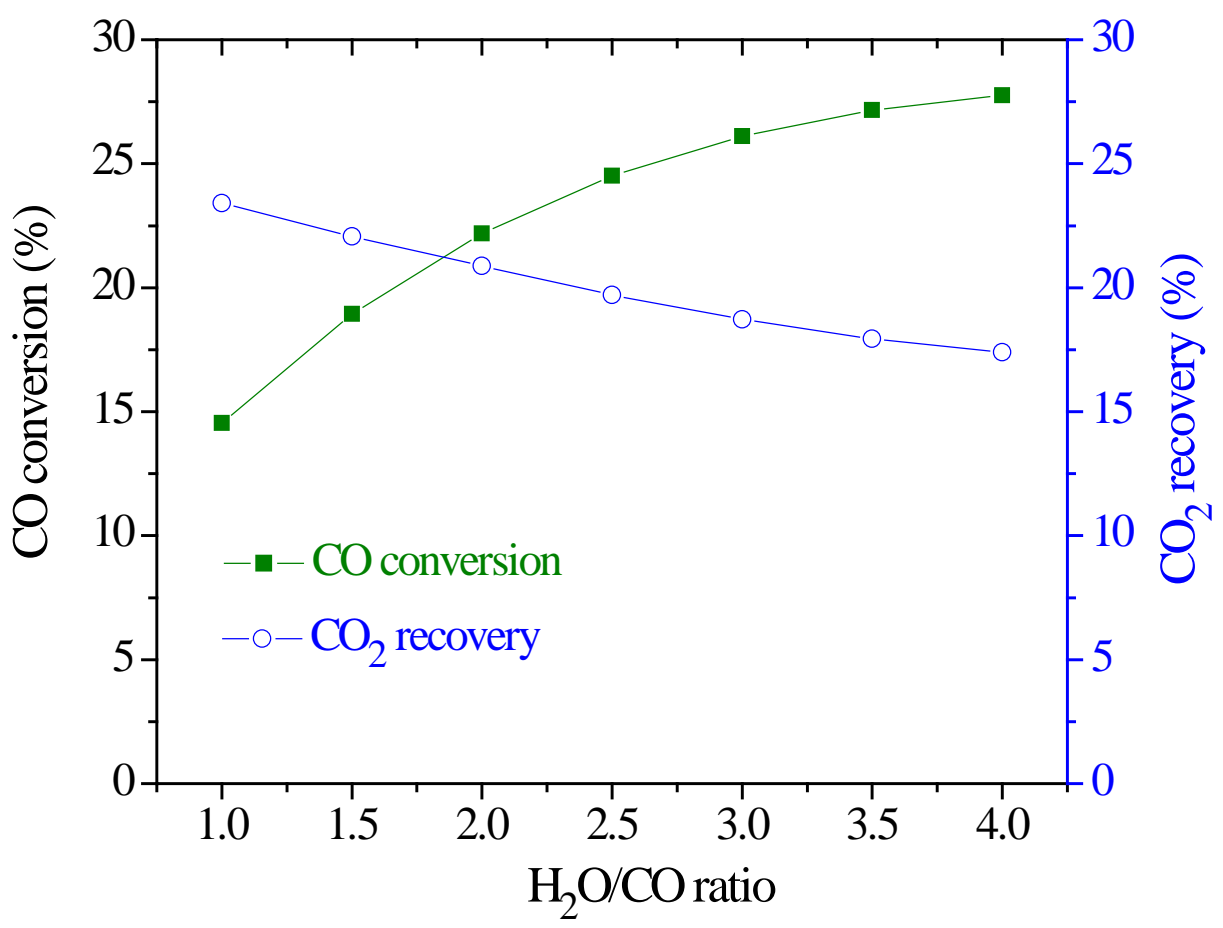

Figure 6: Performance of dual phase membrane reactor as a function of steam to CO ratio at $900{ }^{\circ} \mathrm{C}$. Feed side: simulated syngas flow rate $20 \mathrm{~mL} \cdot \mathrm{min}^{-1}, \mathrm{~N}_{2}$ flow rate $10 \mathrm{~mL} \cdot \mathrm{min}^{-1}$; Sweep side: He flow rate $60 \mathrm{~mL} \cdot \mathrm{min}^{-1}$. The pressure at feed and permeate sides are both 1 bar.

Figure 7 shows the effect of syngas flow rate on the reaction performance at $900{ }^{\circ} \mathrm{C}$. Both $\mathrm{CO}$ conversion and $\mathrm{CO}_{2}$ recovery decrease upon increasing the syngas flow rate. When the flow rate is $10 \mathrm{ml} \cdot \mathrm{min}^{-1}$, the $\mathrm{CO}$ conversion and $\mathrm{CO}_{2}$ recovery are $37.4 \%$ and $33.5 \%$, respectively. However, the higher syngas flow rate increases the space velocity and reduces the residence time for WGS reaction, resulting in the decrease of CO conversion. Enick and coworkers [19] also observed that during the WGS reaction the CO conversion could be seriously reduced from $99.7 \%$ to $55 \%$ by decreasing the residence time from 2 s to $0.7 \mathrm{~s}$. Additionally, the higher syngas flow rate has negative effect on $\mathrm{CO}_{2}$ removal through the membrane. Too much unreacted $\mathrm{CO}$ and steam in the feed greatly reduces the $\mathrm{CO}_{2}$ partial pressure, leading to the low $\mathrm{CO}_{2}$ permeation flux and decrease of $\mathrm{CO}_{2}$ recovery. In other words, the significant role of dual-phase membrane in the membrane reactor is restrained at high syngas flow rate. Therefore, the match between the syngas flow rate and the WGS reaction rate, and match between the $\mathrm{CO}_{2}$ production rate from the reaction and the $\mathrm{CO}_{2}$ removal rate through the membrane are critical. 


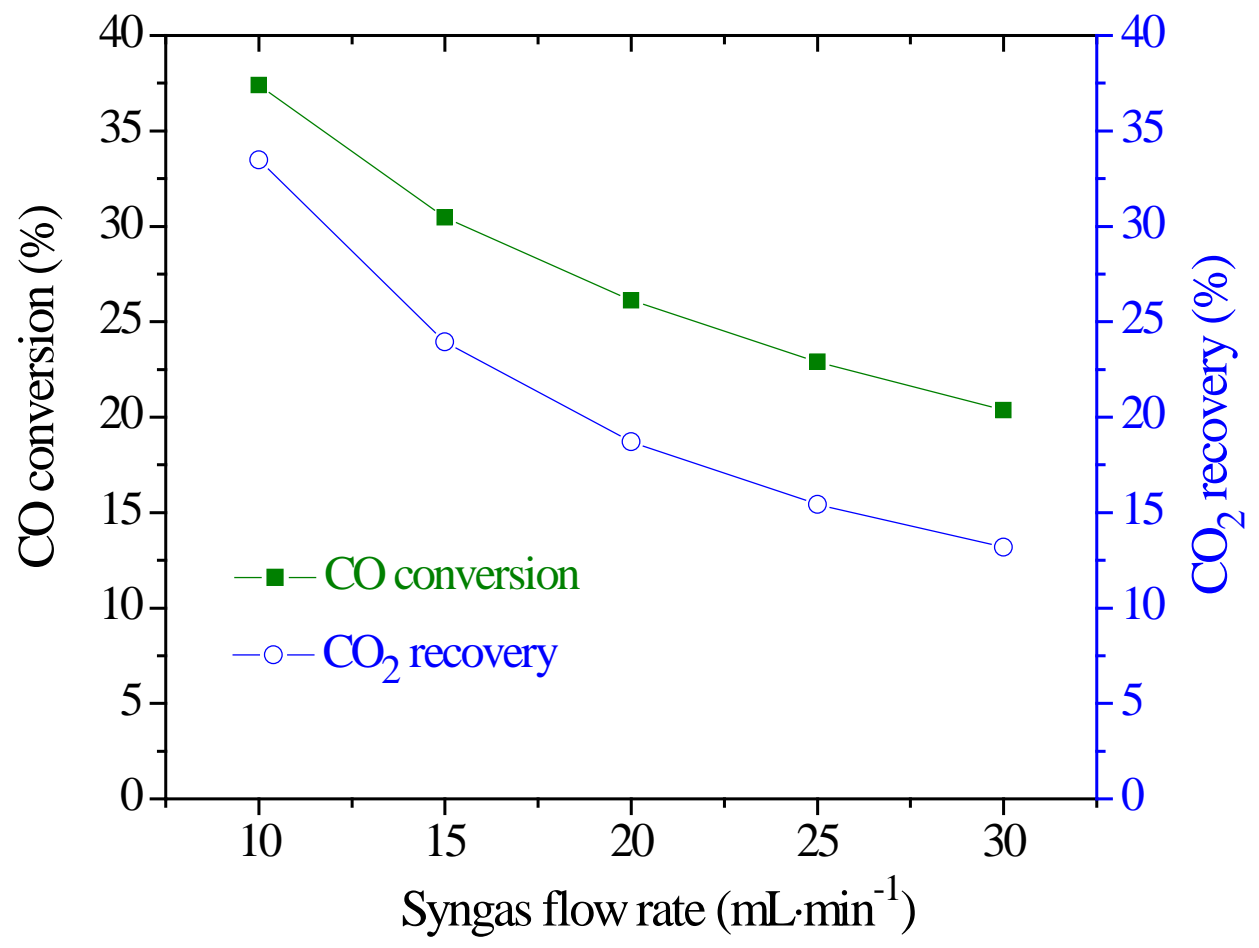

Figure 7: Performance of dual phase membrane reactor as a function of syngas flow rate at $900{ }^{\circ} \mathrm{C}$. Feed side: simulated syngas flow rate $10-30 \mathrm{~mL} \cdot \mathrm{min}^{-1}, \mathrm{~N}_{2}$ flow rate $10 \mathrm{~mL} \cdot \mathrm{min}^{-1}$, steam to CO ratio is 3.0 ; Sweep side: He flow rate $60 \mathrm{~mL} \cdot \mathrm{min}^{-1}$. The pressure at feed and permeate sides are both 1 bar.

\subsection{Membrane reactor stability}

For practical application of dual phase membranes, high thermal and chemical stability under harsh syngas WGS reaction environment is required. Therefore, the long-term stability of the SDC-carbonate membrane reactor was studied. First, the membrane was continuously operated for $30 \mathrm{~h}$ at $900{ }^{\circ} \mathrm{C}$ and then slowly cooling down to room temperature. After resealing, the membrane was heated to $900{ }^{\circ} \mathrm{C}$ for next test. Such a thermal cycle measurement was carried out for four times (0-30h; 30-58h; 58-84h; 84-112h). As shown in Figure 8, the $\mathrm{CO}$ conversion, $\mathrm{CO}_{2}$ recovery and $\mathrm{CO}_{2}$ flux maintain at around $26.2 \%, 18.4 \%$ and $2.7 \times 10^{-3} \mathrm{~mol} \cdot \mathrm{m}^{-2} \cdot \mathrm{s}^{-1}$, respectively. After long-term testing, the morphology of the membrane was analyzed (Figure 9). The surface of sweep side is slightly eroded, which may be caused by the minor decomposition of carbonate under the low $\mathrm{CO}_{2}$ partial pressure at high temperature. However, the thickness of the eroded layer is only 1-2 $\mu \mathrm{m}$. In contrast, the surface of reaction side is still dense and the corrosion of syngas and steam atmospheres to 
the membrane is not obvious.

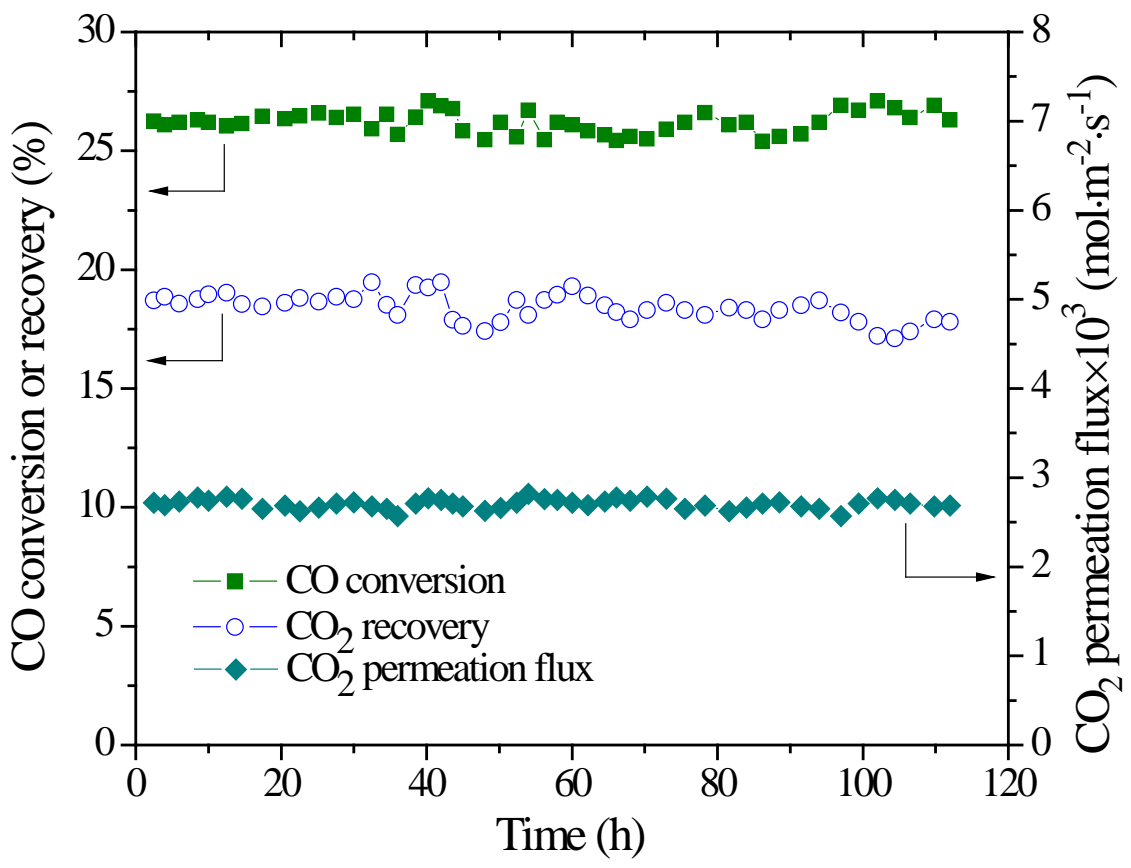

Figure 8: The long-term stability of SDC-carbonate tubular dual phase membrane reactor for syngas water gas shift reaction at $900{ }^{\circ} \mathrm{C}$ without catalyst. Thickness of the membrane is about $1.5 \mathrm{~mm}$. Feed side: simulated syngas flow rate $20 \mathrm{~mL} \cdot \mathrm{min}^{-1}, \mathrm{~N}_{2}$ flow rate $10 \mathrm{~mL} \cdot \mathrm{min}^{-1}$, and $\mathrm{H}_{2} \mathrm{O}$ (steam) to $\mathrm{CO}$ molar ratio is 3.0; Sweep side: He flow rate $60 \mathrm{~mL} \cdot \mathrm{min}^{-1}$. The pressure at feed and permeate sides are both 1 bar.

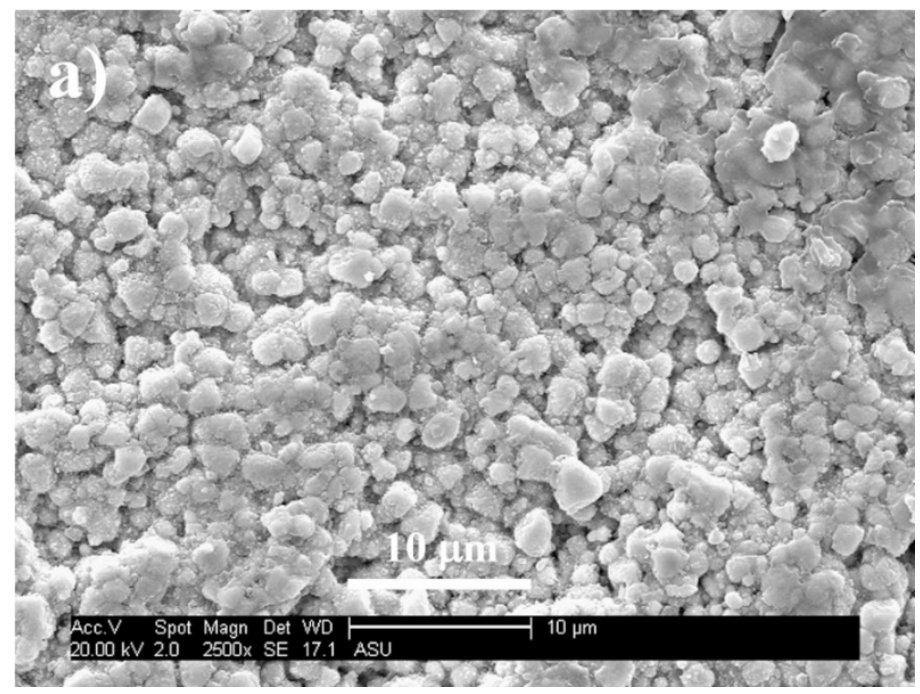




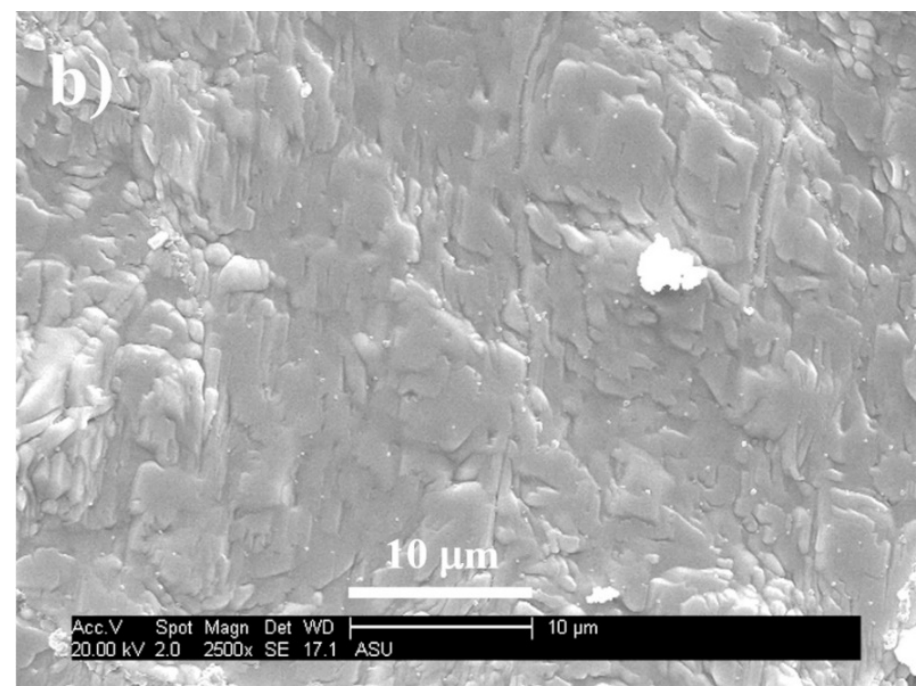

Figure 9: SEM images of the SDC-carbonate membrane after long-term syngas water gas shift reaction: (a) outer surface (sweep side) and (b) inner surface (reaction side).

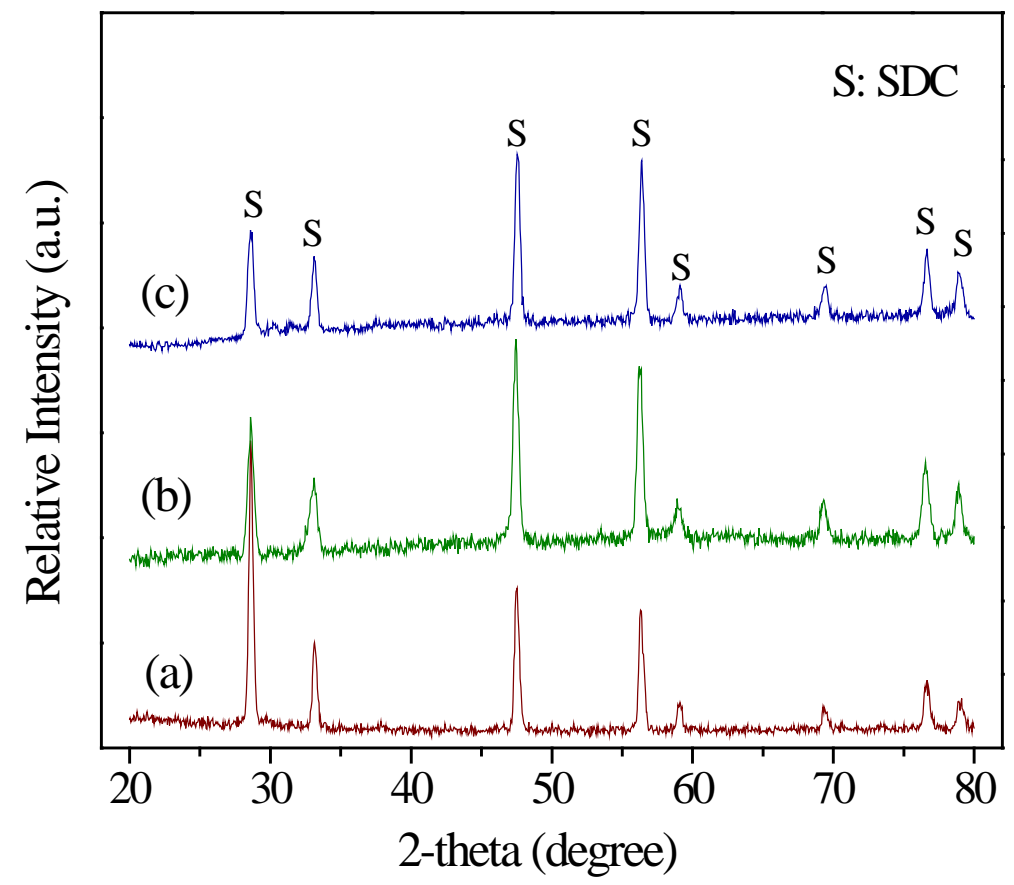

Figure 10: XRD pattern of membrane after long-term syngas water gas shift reaction: (a) fresh membrane; (b) outer surface (sweep side); (c) inner surface (reaction side).

The crystal structures of the membrane before and after long-term reaction were also analyzed (Figure 10). Both reaction side and sweep side maintain full fluorite structure and no obvious impurity phases are observed. These results indicate that the SDC-carbonate dual phase membrane is stable under the syngas WGS reaction environment. Accordingly, we can 
conclude that SDC-carbonate dual phase membrane has high potential for practical applications in high temperature $\mathrm{CO}_{2}$ separation.

For industrial application of this new proposed process, further improvement of CO conversion and $\mathrm{CO}_{2}$ recovery is desired. The WGS reaction in the membrane reactor is also influenced by other experimental conditions such as feed pressure and membrane surface area to reaction zone volume ratio, which could not be studied due to the constraint in experimental conditions (e.g., sealing issue prevented experiments at higher temperature). Considering the membrane reactor feature, one of the possible routes for the improvement is to increase the feed pressure. WGS reaction equilibrium itself will not be affected by pressure because it is a constant volume reaction. However, in the dual phase membrane reactor, high operation pressure at the reaction side (feed side) is beneficial for the transport of the produced $\mathrm{CO}_{2}$ through the membrane, resulting in the shift of the reaction equilibrium toward $\mathrm{H}_{2}$ and $\mathrm{CO}_{2}$ production, promoting the $\mathrm{CO}$ conversion and $\mathrm{CO}_{2}$ recovery. Experimental tests on WGS reaction on a disk SDC-carbonate membrane reactor using graphite seal [35] (with $\mathrm{CO}$ and $\mathrm{H}_{2} \mathrm{O}$ feed at $700{ }^{\circ} \mathrm{C}$ ) show an increase in $\mathrm{CO}$ conversion and $\mathrm{CO}_{2}$ recovery respectively by $52 \%$ and $454 \%$ as the feed pressure increase from 1 atm to 5 atm. It is worth noting that the pressure of practical coal gasification gas may be higher than 20 bar. Such a high feed pressure is of great benefit to the $\mathrm{CO}_{2}$ removal through SDC-carbonate membrane, therefore facilitating the improvement of both $\mathrm{CO}$ conversion and $\mathrm{CO}_{2}$ recovery.

\section{Conclusions}

This work demonstrates a new process for hydrogen production from high temperature syngas WGS reaction in a SDC-carbonate dual phase membrane reactor with simultaneously $\mathrm{CO}_{2}$ removal. The membranes show good $\mathrm{CO}_{2}$ permeation flux and high thermal and chemical stability under syngas WGS reaction environment. The removal of $\mathrm{CO}_{2}$ by dual phase membrane from reaction process promotes the conversion of $\mathrm{CO}$ at high temperatures without a catalyst. Further improvement of $\mathrm{CO}_{2}$ separation performance in practical application is possible by increasing the feed pressure. This work also confirms the reliability of SDC-carbonate dual phase membranes for high temperature $\mathrm{CO}_{2}$ removal from industrial processes, such as IGCC. 


\section{Acknowledgments}

This work was financially supported by the Department of Energy (DE-FE000470). We acknowledge B. Lu for assistance in some of the experiments.

\section{Reference}

[1] J.D. Figueroa, T. Fout, S. Plasynski, H. McIlvried, R.D. Srivastava, Advances in $\mathrm{CO}_{2}$ capture technology—The U.S. Department of Energy's carbon sequestration program, Int. J. Green. Gas Control 2 (2008) 9-20.

[2] P.H. Stauffer, G.N. Keating, R.S. Middleton, H.S. Viswanathan, K.A. Berchtold, R.P. Singh, R.J. Pawar, A. Mancino, Greening coal: Breakthroughs and challenges in carbon capture and storage, Environ. Sci. Technol. 45 (2011) 8597-8604.

[3] A.A. Olajire, $\mathrm{CO}_{2}$ capture and separation technologies for end-of-pipe applications - A review, Energy 35 (2010) 2610-2628.

[4] J. Franz, V. Scherer, An evaluation of $\mathrm{CO}_{2}$ and $\mathrm{H}_{2}$ selective polymeric membranes for $\mathrm{CO}_{2}$ separation in IGCC processes, J. Membr. Sci. 359 (2010) 173-183.

[5] C.A. Scholes, K.H. Smith, S.E. Kentish, G.W. Stevens, $\mathrm{CO}_{2}$ capture from pre-combustion processes—Strategies for membrane gas separation, Int. J. Green. Gas Control 4 (2010) 739-755.

[6] P. Luis, T.V. Gerven, B.V. der Bruggen, Recent developments in membrane-based technologies for $\mathrm{CO}_{2}$ captureProg, Energ. Combust. 38 (2012) 419-448.

[7] K. Ramasubramanian, Y. Zhao, W.S. Winston Ho, $\mathrm{CO}_{2}$ capture and $\mathrm{H}_{2}$ purification: Prospects for $\mathrm{CO}_{2}$-selective membrane processes, AIChE J. 59 (2013) 1033-1045.

[8] J. Caro, M. Noack, Zeolite membranes - Recent development and progress, Micropor. Mesopor. Mater. 115 (2008) 215-233.

[9] A.S. Augustine, Y.H. Ma, N.K. Kazantzis, High pressure palladium membrane reactor for the high temperature water-gas shift reaction, Int. J. Hydrogen Energy 36 (2011) 53505360 . 
[10] J. Catalano, F. Guazzone, I.P. Mardilovich , N.K. Kazantzis, Y.H. Ma, Hydrogen production in a large scale water-gas shift Pd-based catalytic membrane reactor, Ind. Eng. Chem. Res. 52 (2013) 1042-1055.

[11] J.L. Li, H. Yoon, T.K. Oh, E.D. Wachsman, High temperature $\mathrm{SrCe}_{0.9} \mathrm{Eu}_{0.1} \mathrm{O}_{3-\delta}$ proton conducting membrane reactor for $\mathrm{H}_{2}$ production using the water-gas shift reaction, Appl. Catal. B: Environ. 92 (2009) 234-239.

[12] Y. Chen, Q. Liao, Z. Li, H. Wang, Y. Wei, A. Feldhoff, J. Caro, A $\mathrm{CO}_{2}$-stable hollow-fiber membrane with high hydrogen permeation flux, AIChE J. 61 (2015) 19972007.

[13] S. Battersby, S. Smart, B. Ladewig, S. Liu, M.C. Duke, V. Rudolph, J.C.D. da Costa, Hydrothermal stability of cobalt silica membranes in a water gas shift membrane reactor, Sep. Purif. Technol. 66 (2009) 299-305.

[14] C. Yacou, S. Smart, J.C.D. da Costa, Long term performance cobalt oxide silica membrane module for high temperature H2 separation, Energy Environ. Sci. 5 (2012) $5820-5832$.

[15] Z. Tang, S.J. Kim, G.K. Reddy, J. Dong, P. Smirniotis, Modified zeolite membrane reactor for high temperature water gas shift reaction, J. Membr. Sci. 354 (2010) 114-122.

[16] H.B. Wang, X.L. Dong, Y.S. Lin, Highly stable bilayer MFI zeolite membranes for high temperature hydrogen separation, J. Membr. Sci. 450 (2014) 425-432.

[17] M.V. Ciocco, B.D. Morreale, K.S. Rothenberger, B.H. Howard, R.P. Killmeyer, R.M. Enick and F. Bustamante, Water-gas shift membrane reactor studies, NETL Report, 2005.

[18] F. Bustamante, R.M. Enick, R.P. Killmeyer, B.H. Howard, K.S. Rothenberger, A.V. Cugini, B.D. Morreale and M.V. Ciocco, Uncatalyzed and wall-catalyzed forward watergas shift reaction kinetics, AIChE J. 51 (2005) 1440-1454.

[19] O. Iyoha, R. Enick, R. Killmeyer, B. Howard, M. Ciocco, B. Morreale, $\mathrm{H}_{2}$ production from simulated coal syngas containing $\mathrm{H}_{2} \mathrm{~S}$ in multi-tubular Pd and 80 wt\% Pd-20 wt\% Cu membrane reactors at 1173 K, J. Membr. Sci. 306 (2007) 103-115.

[20] D.P. Harrison, Sorption-enhanced hydrogen production: A review, Ind. Eng. Chem. Res. 47 (2008) 6486-6501.

[21] H.M. Jang, K.B. Lee, H.S. Caram, S. Sircar, High-purity hydrogen production through 
sorption enhanced water gas shift reaction using $\mathrm{K}_{2} \mathrm{CO}_{3}$-promoted hydrotalcite, Chem. Eng. Sci. 73 (2012) 431-438.

[22] M.S. Duyar, R.J. Farrauto, M.J. Castaldi, T.M. Yegulalp, In situ $\mathrm{CO}_{2}$ capture using $\mathrm{CaO} / \gamma-\mathrm{Al}_{2} \mathrm{O}_{3}$ washcoated monoliths for sorption enhanced water gas shift reaction, Ind. Eng. Chem. Res. 53 (2014) 1064-1072.

[23] N. Du, H.B. Park, M.M. Dal-Cina, M.D. Guiver, Advances in high permeability polymeric membrane materials for $\mathrm{CO}_{2}$ separations, Energy Environ. Sci. 5 (2012) 73067322.

[24] T.C. Merkel, H. Lin, X. Wei, R. Baker, Power plant post-combustion carbon dioxide capture: An opportunity for membranes, J. Membr. Sci. 359 (2010) 126-139.

[25] M. Anderson, H.B. Wang, Y.S. Lin, Inorganic membranes for carbon dioxide and nitrogen separation, Rev. Chem. Eng. 28 (2012) 101-121.

[26] X. Gu, J. Dong, T.M. Nenoff, Synthesis of defect-free FAU-type zeolite membranes and separation for dry and moist $\mathrm{CO}_{2} / \mathrm{N}_{2}$ mixtures, Ind. Eng. Chem. Res. 44 (2005) 937-944.

[27] Y. Sakamoto, K. Nagata, K. Yogo, K. Yamada, Preparation and $\mathrm{CO}_{2}$ separation properties of amine-modified mesoporous silica membranes, Micropor. Mesopor. Mater. 101 (2007) 303-311.

[28] S. Li and C.Q. Fan, High-flux SAPO-34 membrane for $\mathrm{CO}_{2} / \mathrm{N}_{2}$ separation, Ind. Eng. Chem. Res. 49 (2010) 4399-4404.

[29] S.J. Chung, J.H. Park, D. Li, J.-I. Ida, I. Kumakiri, J.Y.S. Lin, Dual-phase Metal-Carbonate membrane for high-temperature carbon dioxide separation, Ind. Eng. Chem. Res. 44 (2005) 7999-8006.

[30] M. Anderson, Y.S. Lin, Carbonate-ceramic dual-phase membrane for carbon dioxide separation, J. Membr. Sci. 357 (2010) 122-129.

[31] Z. Rui, M. Anderson, Y. Li, Y.S. Lin, Ionic conducting ceramic and carbonate dual phase membranes for carbon dioxide separation, J. Membr. Sci. 417-418 (2012) 174-182.

[32] B. Lu, Y.S. Lin, Synthesis and characterization of thin ceramic-carbonate dual-phase membranes for carbon dioxide separation, J. Membr. Sci. 444 (2013) 402-411.

[33] J. Ortiz-Landeros, T. Norton, Y.S. Lin, Effects of support pore structure on carbon dioxide permeation of ceramic-carbonate dual-phase membranes, Chem. Eng. Sci. 104 
(2013) 891-898.

[34] X.L. Dong, J. Ortiz-Landeros, Y. S. Lin, An asymmetric tubular ceramic-carbonate dual phase membrane for high temperature $\mathrm{CO}_{2}$ separation, Chem. Commun. 49 (2013) 96549656.

[35] T.T. Norton, B. Lu, Y.S. Lin, Carbon dioxide permeation properties and stability of samarium-doped-ceria carbonate dual-phase membranes, J. Membr. Sci. 467 (2014) 244252.

[36] J. L. Wade, C. Lee, A.C. West, K.S. Lackner, Composite electrolyte membranes for high temperature $\mathrm{CO}_{2}$ separation, J. Membr. Sci. 369 (2011) 20-29.

[37] N. Xu, X. Li, M. A. Franksc, H. Zhaob, K. Huang, Silver-molten carbonate composite as a new high-flux membrane for electrochemical separation of $\mathrm{CO}_{2}$ from flue gas, $\mathrm{J}$. Membr. Sci. 401-402 (2012) 190-194.

[38] L. Zhang, N. Xu, X. Li, S. Wang, K. Huang, W.H. Harris, W.K.S. Chiu, High $\mathrm{CO}_{2}$ permeation flux enabled by highly interconnected three-dimensional ionic channels in selective $\mathrm{CO}_{2}$ separation membranes, Energy Environ. Sci. 5 (2012) 8310-8317.

[39] L. Zhang, Y. Gong, J. Yaggie, S. Wang, K. Romito, K. Huang, Surface modified silver-carbonate mixed conducting membranes for high flux $\mathrm{CO}_{2}$ separation with enhanced stability, J. Membr. Sci. 453 (2014) 36-41.

[40] M. Zuo, S. Zuo, X. Y. Tan, B. Meng, N. T. Yang, S. M. Liu, Ionic conducting ceramiccarbonate dual phase hollow fibre membranes for high temperature carbon dioxide separation, J. Membr. Sci. 458 (2014) 58-65.

[41] S.G. Patrício, E. Papaioannou, G. Zhang, I. S. Metcalfe, F. M. B. Marques, High performance composite $\mathrm{CO}_{2}$ separation membranes, J. Membr. Sci. 471 (2014) 211-218.

[42] X.L. Dong, H.B. Wang, Z.B. Rui, Y.S. Lin, Tubular dual-layer MFI zeolite membrane reactor for hydrogen production via the WGS reaction: Experimental and modeling studies, Chem. Eng. J. 268 (2015) 219-229. 
Graphical Abstract

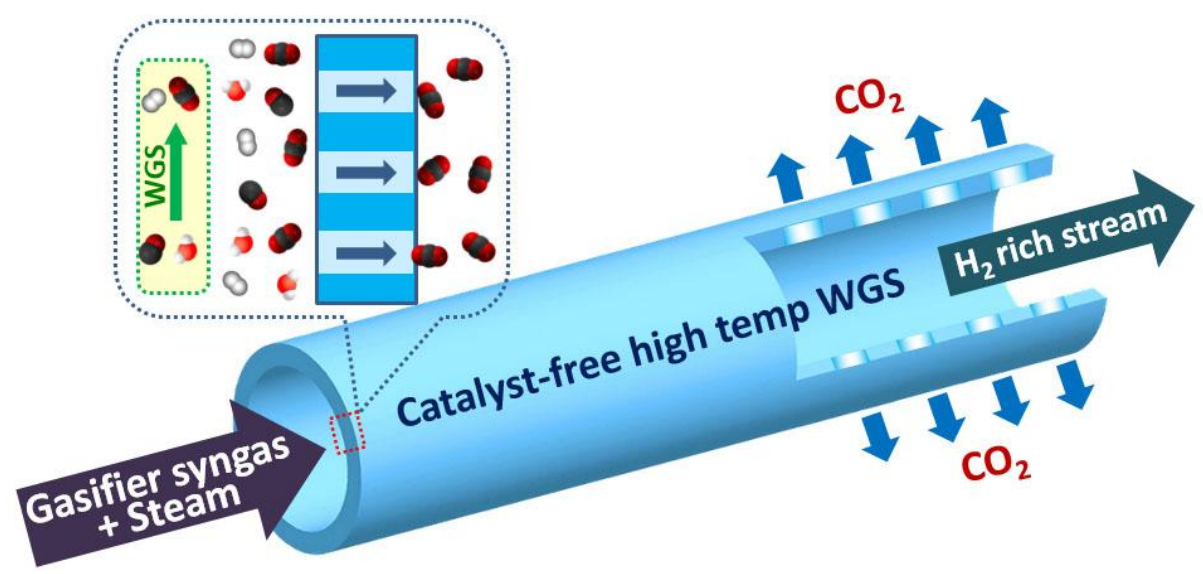

